This is a revised personal version of the text of the final journal article. The Version of Record of this manuscript has been published and is available in Environmental Technology on 02 December 2014. http://www.tandfonline.com/, DOI: 10.1080/09593330.2014.982716.

The full citation is:

T.W. Chu, S. Heaven \& L. Gredmaier (2014): Modelling fuel consumption in kerbside source segregated food waste collection: separate collection and co-collection, Environmental Technology, DOI: 10.1080/09593330.2014.982716

\title{
Modelling fuel consumption in kerbside source segregated food waste collection: separate collection and co-collection
}

\section{Author names and affiliations}

T.W. Chu*, S. Heaven and L. Gredmaier

Faculty of Engineering and the Environment, University of Southampton, Southampton, UK

\begin{abstract}
Source separated food waste is a valuable feedstock for renewable energy production through anaerobic digestion, and a variety of collection schemes for this material have recently been introduced. The aim of this study was to identify options that maximize collection efficiency and reduce fuel consumption as part of the overall energy balance. A mechanistic model was developed to calculate the fuel consumption of kerbside collection of source segregated food waste, co-mingled dry recyclables and residual waste. A hypothetical city of 20,000 households was considered and nine scenarios were tested with different combinations of collection frequencies, vehicle types and waste types. The results showed that the potential fuel savings from weekly and fortnightly co-collection of household waste range from $7.4 \%$ to $22.4 \%$ and $1.8 \%$ to $26.6 \%$, respectively, when compared to separate collection. A compartmentalized vehicle split 30:70 always performed better than one with two compartments of equal size. Weekly food waste collection with alternate weekly collection of the recyclables and residual waste by two-compartment collection vehicles was the best option to reduce the overall fuel consumption.
\end{abstract}

Keywords: collection; food waste; collection system; vehicle; fuel consumption

\section{Introduction}

Food waste is a major component of municipal solid waste in many countries, and its disposal in landfill may have adverse effects on the economy and the environment.[1] According to the waste management hierarchy minimization is the preferred option, but there will always be a component of unavoidable waste for which effective management strategies are needed. In Europe, the EU Landfill Directive (1999/31/EC) created a momentum to remove biodegradable materials from the waste stream. More recently the focus in several countries has moved specifically onto food waste. In the UK, for example, the Scottish government amended its Waste (Scotland) Regulations 2012 to ban the disposal to landfill of household bio-wastes, including food waste, and local authorities are required to provide source 
segregated food waste collections to all households by the end of 2015.[2] Although separate collection of food waste is not yet mandatory in England,[3] the issue is highly topical, with industry and all political parties actively discussing minimization and a ban on landfilling.[47]

Over 70 local authorities in the UK offer a weekly food waste collection.[8] In many cases this was introduced by simply adding a separate service to the existing waste collection, with food waste being collected in a single-compartment vehicle. In order to maximize collection efficiency and reduce operating costs, however, local authorities have started to introduce different types of refuse collection vehicle (RCV). Currently, the two-compartment collection vehicle is gaining popularity among local authorities that collect three separate waste fractions. When there is an increase in the number of streams for source separation, multicompartment collection vehicles may become attractive. Only limited information, however, is available to support local authorities in their choice of collection vehicle and scheme. Vehicles are usually selected based on the experience of other users, through word of mouth or promotional materials. Most previous work on compartmentalized vehicles has looked at goods delivery, and studies relevant to waste collection are rare.[9,10]

While a number of studies have evaluated the performance of food waste collections,[11-13] there is still room for discussion on which systems may be optimal with respect to their performance and energy consumption in different situations.[14] This is especially important when food waste is to be used as a feedstock for renewable energy production through anaerobic digestion. An efficient system is expected to minimize the energy used in collection and transportation, thus reducing the energy inputs into the overall process and increasing the net energy yield. The current study investigated energy use in collection of household waste, with the following main objectives:

- To evaluate how capture rates affect the energy required for collection of the whole kerbside-collected household waste stream;

- To determine which scenarios show the best and worst performance in terms of total fuel consumption for household waste collection;

- To compare the fuel consumption for single collection and co-collection of household waste, and

- To determine which vehicle types are the best at varying capture rates.

\section{Methodology}

\section{Description of the model}

The mechanistic model for waste collection developed in the current work was based on earlier models by Everett and Shahi [15] and Sonesson [16]. Everett and Shahi [15] constructed a model based on the time spent in collecting material in order to study the kerbside collection of yard waste. The model could estimate route time based on time between stops, time spent on non-productive tasks, walking time and sorting time. The model was useful for comparing the efficiency of different collection methods for identical collection routes, and for predicting the required size of the vehicle fleet and the effect of such parameters as set-out rate. Their model, however, did not consider fuel consumption. Sonesson [16] developed a mathematical model to calculate fuel consumption and time spent 
during waste collection using MATLAB/SIMULINK software. The number of stops, collection frequency, and fuel consumption during hauling, collection and stopping were taken into account in the calculation of energy consumption. Only the payload of the collection vehicle was considered, however, which may lead to errors when the number of pick-up points is in fact limited by the volume of a compartment.

The current model uses a deterministic approach to estimate the fuel consumption taking into account the service time, and the volume and load capacity of the collection vehicle. The model was implemented as a Microsoft Excel spreadsheet, and consists of four components: definition of input data (e.g. waste stream composition and collection parameters), determination of limiting factors, specification of collection rounds, and calculation of fuel consumption. The round size and the number of rounds are calculated to allow estimation of the total travelling distance, including collection and transportation stages. The minimum round size is determined based on three factors: weight capacity of the vehicle, the volume capacity of each compartment, and time available per working day (service time). The limiting value is then used for calculation of the $\backslash$ number of collection rounds, by dividing the total number of households by the round size. Travelling distance in the collection area is found by multiplying an average distance between collection points by the total number of households, while the total distance in transportation is obtained by multiplying the number of collection rounds and the average distance between collection area and unloading site (e.g. transfer station, treatment plant or disposal point).

The equations provided by the European Environment Agency EMEP Emission Inventory Guidebook [17] were used to estimate the fuel consumption of RCVs. These take into account the gross weight and emissions standards for the vehicle, and the road gradient. Fuel consumption for refuse collection is likely to be higher than that of a typical heavy duty vehicle, however, due both to the use of hydraulic equipment for bin lifting and the 'stopand-go' driving pattern during the collection phase.[18,19] A correction factor of 1.35 was therefore applied to the calculated fuel consumption during collection.[18] The average road gradient was taken as zero on the assumption that the vehicle returns to its start point each day, and the higher fuel consumption in upgrade road sections could be compensated for by the lower consumption on downgrade sections.[20] When calculating fuel consumption for the collection system, the travelling distance, average speeds and percentage laden of vehicle in the collection and transportation stages were considered.

The input data and parameter values used in modelling are presented in Table 1. The working hours are the total length of a working day, including time for non-productive activities such as breaks: a value of 6 hours was assumed based on the average working hours for household waste collection in the UK. The time for intermediate unloading is the time to unload when more than one load is deposited per day, while the time at unloading site is the time for final unloading at the end of the round when vehicle queuing times may be longer. The bin pick-up time includes the time required for the collector to leave the vehicle cab, walk to the bin, pick it, empty it and return it to its original location and go back to the vehicle cab. Based on the size of the bin and the way in which it is emptied, the bin pick-up time was taken as 21.6 seconds for a food waste caddy [11] and 33.0 seconds for kerbside recycling and residual waste bins.[21] The speed in collection is the average speed inside the collection area, from the first to the last collection point. For a densely populated area, the average speeds in collection and transport are assumed to be 10 and $50 \mathrm{~km}$ hour-1 as suggested by Zamorano et al.[22] The model outputs include fuel consumed per tonne of waste collected, total mileage, utilization of compartments in terms of volume and load, total number of collection routes, 
total time spent and the number of collection vehicles required. In this study, the fuel consumption, time spent in collection and distance travelled are reported.

\section{Composition of kerbside household waste}

Household waste composition was based on a detailed survey of local authority collected waste in England,[23] including household residual and recyclable waste collected at the kerbside, at household waste recycling centres and in street bins. The survey classified the waste into 20 categories which for the purposes of this work were combined as follows: Paper and card, Food waste, Garden \& other organic waste, Plastics, Glass, Metals, Wood, Textiles, Waste Electrical and Electronic Equipment (WEEE), and Other. For this study waste composition was recalculated from the reported data to give kerbside collected material only (i.e. excluding waste collected via bring systems). Base on this, each household in England generates on average $869.4 \mathrm{~kg}$ per year of kerbside waste, equivalent to $2.38 \mathrm{~kg}$ per household per day. The estimated average quantities of food waste, recyclables and residual wastes collected are given in Table 2. In this study, food waste means leftover food and food preparation waste such as rinds and peels. Recyclable waste means paper and card, plastics, glass and metals that are collected co-mingled. Residual waste is a mixture of materials including wood, textiles, WEEE, and other wastes, and any recyclables and food waste that have not been captured in the recycling bins. Garden and other organic wastes were assumed to be composted or collected separately.

\section{Scenarios for the collection system}

It was assumed that household waste is collected by a single-compartment or compartmentalized collection vehicle on a weekly or fortnightly basis. A range of Euro 5 heavy duty vehicles were considered, with the specifications given in Table 3. Twincompartment vehicles are rear split-bodied, while the compartments of pod vehicles are split into two parts: front and rear.

A hypothetical city of 20,000 households was used in the study, representing a typical medium-sized town in Europe.[24] Nine scenarios were considered based on some of the most commonly occurring combinations of collection frequencies, vehicle types and waste types. Each scenario was run with capture rates for food waste and recyclables, ranging from $10 \%$ to $100 \%$, as given in Table 4 . In addition, only weekly collection of source separated food waste was considered as this is widely regarded as the maximum acceptable interval in the UK and many other parts of Europe, although practice varies depending on climate and season.

Scenarios were grouped to allow comparison of the difference in fuel consumption with respect to collection frequency, collection method and allocation of waste to different compartments. Scenarios 1, 3, 5 and 7 were compared to illustrate the differences between single collection and co-collection of kerbside household waste on a weekly basis. Scenarios 2, 4 and 9 were considered together to show the difference between alternate weekly collection and fortnightly co-collection of household waste using single and twocompartment RCVs. 


\section{Result and discussion}

\section{Effect of capture rates for food waste and recyclables on fuel consumption per tonne of residual waste collected}

Figures 1 and 2 show fuel consumption per tonne of residual waste collected at different capture rates for food waste and recyclables, under scenarios 1 and 2. At low capture rates for recyclables and food waste there is a significant amount of residual waste to be collected. In both weekly and fortnightly collection, the fuel consumption per tonne for residual waste increases with an increase in capture rates of food waste and of recyclables, as expected. This is due to the reduction in the amount of residual waste collected per week, while the travelling distance remains constant. Although fuel consumption per tonne of residual waste rises, it may still be worthwhile to separate out the food waste as the energy recovered in anaerobic digestion may more than compensate for the additional energy spent in collection.[25]

In weekly residual waste collection, for recyclables capture rates from $10 \%$ to $60 \%$, changes in the food waste capture rate have little effect on the fuel consumption per tonne of residual waste collected. As the capture rate for recyclables rises above $60 \%$, the fuel consumption per tonne of residual waste also rises, by a factor of up to 1.32 as the food waste capture rate increases. On the other hand, changes in recyclable capture rate have a larger effect on fuel consumption, especially when more food waste is captured (Figure 1). The maximum fuel consumption for residual waste collection is up to 1.43 times higher than the minimum.

The fuel consumption per tonne of residual waste with fortnightly collection is shown in Figure 2. As the food waste capture rate increases, the rise in fuel consumption ranges from 1.05 to 1.25 times for recyclable waste capture rates of $10 \%$ to $100 \%$, respectively. When the majority of food waste is captured, from 1.22 to 1.34 times more fuel is used to collect one tonne of residual waste as the capture rate for recyclables rises.

Comparing the fuel consumption of the weekly and fortnightly residual waste collection, it is clear that fortnightly collection of residual waste can save a considerable amount of fuel in comparison with weekly collection. Research on operational schemes has also shown that fortnightly collection of residual waste can enhance the capture rate of food waste. Based simply on fuel use, fortnightly collection of recyclable and residual waste with an additional weekly food waste collection is thus a favoured option. The approach used in the current study provides the necessary information on energy use in collections to allow determination of the overall energy balance for food waste management options.

Model output for diesel fuel consumption per tonne of residual waste in fortnightly collection ranged from 3.74 to $5.4 \mathrm{~L}$ tonne-1. This is slightly higher than the values of 3.3 to $3.6 \mathrm{~L}$ tonne-1 for fortnightly collection of residual waste from single family homes in an urban area of Aarhus, Denmark.[26] Conversely it is less than the value of 5.96 L tonne-1 for residual waste collection in Taipei, Taiwan.[27] It is difficult to suggest reasons for these differences as neither study provides sufficient detail of the collection scheme, such as frequency, vehicle used and amount of waste collected at each household, all of which affect the overall fuel consumption. The results confirm, however, that the model values are in line with those found in real schemes. 


\section{Best and the worst collection system based on different parameters}

For the purposes of comparison, equal capture rates were assumed for food waste and recyclables in this part of the work.

\section{Fuel consumption}

Figure 3 shows the fuel consumption for collection of the whole household waste stream in each scenario at capture rates of $10-100 \%$ for recyclables and food waste. For scenarios using a single-compartment RCV, the model was run for the whole range of RCVs given in Table 3, and the result shown is for the vehicle giving the lowest fuel consumption in each case. Similarly, for twin-compartment vehicles all permutations of waste stream and compartment were tested, and the result shown is for the combination giving the lowest fuel consumption. In general, the fuel consumption in collecting the whole household waste stream decreases when the capture rates for co-mingled recyclables and food waste increase. Scenario 9 has the lowest fuel consumption at the 30-100\% capture rates, while scenario 1 has the highest in all situations. Scenario 6 consumes the least fuel at $10 \%$ capture rates of recyclable and food waste. There is little difference between scenarios 1,3 and 7 , as all of which have their highest fuel consumption for collection of the whole household waste stream at a $10 \%$ capture rate.

\section{Distance travelled}

The total distance travelled per week in the collection of household waste was examined as an indicator of the lifespan of the collection vehicle with respect to wear-and tear and maintenance. Figure 4 shows the best outcome regarding travel distance for the whole household waste collection at 10-100\% capture rates of recyclables and food waste in each scenario. The results showed that the total distance travelled decreases with an increase in the capture rate for recyclables and food waste. Peaks corresponding to sudden increases in distance travelled can be seen in some cases: these are mainly caused by step changes in the number of collection rounds required. It can be seen that scenarios 6 and 9 have the lowest travel distance at low and high capture rates, respectively, while there is no significant difference between these scenarios when capture rates for food waste and recyclable are between $40 \%$ and $80 \%$. Scenarios 1 and 7 have the worst performance with respect to distance travelled at low $(10-20 \%)$ and high $(30-100 \%)$ capture rates for recyclables and food waste.

\section{Total collection time}

The time for collection of the whole household waste stream per week was considered as this gives an indication of the relative costs of labour. The graph in Figure 5 shows the minimum working time per week at each capture rate for food waste and recyclables and scenario. It is apparent that scenario 1 has the worst performance with respect to total collection time per week, while Scenario 9 requires the least time to complete the whole collection at all capture rates.

\section{Comparison of optimal scenarios for collection of the whole household waste stream}

The scenarios were compared with respect to fuel consumption for the whole household waste collection. Scenario 1 was used as a baseline to show the difference between co- 
collection and single collection. The fuel saved by weekly co-collection of household waste compared to scenario 1 ranged from $7.4 \%$ to $22.4 \%$. Scenario 2 was used as the baseline to show the difference between alternate weekly collection and fortnightly co-collection of household waste in single and two-compartment RCVs. It was found that scenarios 4 and 9 use, respectively, $1.8-9.8 \%$ and 8.1-26.6\% less fuel than scenario 2 at capture rates of 30\% or more. At 10-20\% capture rates, the fuel used in co-collection of waste is higher than that in scenario 2 with alternate fortnightly collection of recyclables and residual waste.

Scenarios 1-9 allow comparison of the effect of using single-compartment or split compartment vehicles and of collection frequency on the fuel consumption, distance travelled and time spent. First of all, it is clear that the use of a single-compartment RCV for separate collection of comingled recyclables, food waste and residual waste every week (scenario 1) has the worst performance in terms of fuel consumption, working time and total distance travelled. This result is in agreement with findings reported elsewhere that suggest a singlecompartment vehicle uses more fuel and more time than a compartmentalized vehicle when more fractions of waste are source separated for collection.[28] It is interesting to note, however, that co-collection does not always consume less fuel. The collection frequency does affect the outcome, as clearly shown in the results of this theoretical study.

In the current study, using a compartmentalized vehicle to co-collect any type of wastes with a weekly single collection for rest of the waste (e.g. scenarios 3, 5 and 7) always has higher fuel usage, time required and distance travelled than single collection of recyclable and residual waste every fortnight combined with weekly food waste collection. Putting aside the question of public acceptance of a change in frequency of the household waste collection service, it is clear that provision of fortnightly single collection or co-collection of the recyclable and residual waste with weekly food waste collection minimizes fuel consumption, as well ensuring a good lifespan for the collection vehicle. Among the scenarios examined, the weekly food waste collection with alternate weekly collection of residual or recyclable waste by the two-compartment collection vehicle (scenario 9) was the best collection scheme to operate at most capture rates in terms of fuel consumption. This result therefore adds quantitative evidence to support the choices currently being made by some UK local authorities.[29] In addition, choosing the right type of collection vehicle can further reduce the fuel consumption and the time spent on collection activity, as demonstrated in scenario 9. Both scenarios 6 and 9 gave similar results in terms of total distance travelled and time spent, indicating that weekly co-collection of the recyclables and food waste with a singlecompartment vehicle to collect the residual waste every two weeks is another preferable option, although it is not common practice at the moment.

In this study, capture rates for food waste and recyclable waste varied from $10 \%$ to $100 \%$ in every scenario. In reality, very low capture rates for recyclable materials are rare, even when a new household separation collection is first rolled out. Capture rates of food waste and recyclables usually fall between $20-60 \%$ and $50-80 \%$, respectively, with variations due to factors such as demography and the length of time for which the collection scheme has operated (7 July 2012 e-mail from Andy Bond to me; unreferenced, see 'Notes'). The full range of capture rates was considered, however, both to provide a complete picture and to illustrate the potential of the model to explore the effect of changing tonnages of these components. 


\section{Refuse collection vehicle}

\section{Single-compartment collection vehicle}

Table 5 shows the optimal collection vehicles in terms of fuel consumption for each collection frequency and capture rate. In weekly food waste collection, the 18 and 26-tonne single-compartment collection vehicles did not have the best performance at any capture rates. However, the 18-tonne single-compartment RCV consumes the least diesel at 70-100\% capture rates in weekly co-mingled recyclables waste collection. With regard to the weekly residual waste collection, the 26-tonne single-compartment RCV used the least fuel at low capture rates for recyclables and food waste. In the fortnightly recyclable collection, the performance of the 18-tonne RCV was good at high capture rates. The 26-tonne singlecompartment RCV is the best vehicle for collection of residual waste in the fortnightly residual waste collection.

\section{Two-compartment collection vehicle}

Comparing all of the scenarios, it can be observed that the performance of the pod vehicle is better than the rear split collection vehicle in terms of fuel consumption. Among the pod vehicles, the Duo3-type collection vehicle gave the best option at most capture rates for recyclables and food waste. The suitability of the collection vehicles in different collection system at different capture rates is given in Table 6.

Providing a tool to help users choose the optimal RCV for different circumstances was one of the goals of this research. As expected, the results of the study confirm that a small RCV is ideal for the collection of smaller amounts of waste from each pick-up point, such as food waste, while a larger vehicle such as the 26-tonne RCV is especially good for residual waste collection. Regarding co-collection of household waste, two types of compartmentalized vehicles were considered. Based on this theoretical study, it appears that the 50:50 split is better than the 30:70 split for any size of rear split vehicle. When considering all the compartmentalized collection vehicles in this study, the pod vehicle performed better than the rear split vehicle in most cases in terms of fuel consumption, especially for large vehicles.

Generally speaking, the collection vehicle is usually limited by compartment volume rather than vehicle payload during co-collection of household waste. Therefore, the volume and the split ratio of the compartments can be considered when selecting a suitable collection vehicle. Based on specific fuel consumption, in this theoretical study the Duo3 vehicle performed better than the Twin3 vehicle, although the volume ratios of the compartments are about 30:70 in both cases. This is because the front compartment of the Duo3 vehicle is $1 \mathrm{~m} 3$ bigger than the smallest rear compartment in the Twin3 collection vehicle, allowing more households to be visited before the compartment is full. In comparison, although the volume of the 50:50 split vehicles is larger at $10 \mathrm{~m} 3$, this may not always be ideal for collection because the second compartment fills more quickly than the largest compartment in the 30:70 split vehicles. Thus, in order to further improve collection efficiency, it is suggested that the split ratios should be kept at 30:70 and if possible the volumes of both compartments should be increased. Increasing the vehicle payload by the use of a lighter material for the compartment body could theoretically improve performance, but may not be feasible in practice due to the requirement for robustness. When considering the use of a larger compartmentalized collection vehicle, several factors must be considered such as the average time needed for collection per day, and the width of roads and other potential bottlenecks. 
Also, the balance between the size of compartment and the collection time must always be considered unless shift working is practiced.

\section{Limitations of the study}

The co-collection model used in the current study does not necessarily reflect the real situation: for example a 100\% set out rate for all bins and equal capture rates for recyclable and food waste were applied in all cases. In practice, set out rates for residual waste may be higher than that for recyclables, while both set-out and capture rates for source segregated food waste may be lower than that for other materials. In this case, the large compartment may potentially be fully utilized for the residual waste before the other compartment is full. These factors may lead to over-estimation or, more commonly, under-estimation of fuel consumption. Although differences between theoretical results and real data are expected, it is difficult to estimate the size of this difference. Local authorities and waste collection contractors usually record basic information such as the number of households per collection round, the amount of waste collected per vehicle, and sometimes even the participation rate in the scheme; but more detailed information such as how much waste is collected at each household and the passing rate of the vehicle in each collection round is often unavailable. One approach to the issues raised above might be to construct a probabilistic model for waste collection, to allow more accurate estimation of the likely value of outputs. This may be impractical, however, because of the lack of sufficient data for model validation. The current approach of using a deterministic model which can be combined with sensitivity analysis thus appears to offer the most promising tool for comparing the expected output from different scenarios and conditions. Further aspects that should be considered in future studies include looking at:

- The same scenarios but at less than $100 \%$ set-out rate;

- The same scenarios but with different capture rates for different recyclable components; and

- The number of vehicles required as an indicator of investment costs.

\section{Conclusions}

In this study, fuel consumption in the collection of the co-mingled recyclables materials, source-segregated food waste and residual waste was investigated using a case study of a hypothetical city of 20,000 households. The results are based on a set of representative assumptions for a number of typical scenarios, but the model clearly provides a powerful tool for exploring alternatives. The results from scenario modelling showed that, for the range of conditions considered:

- Weekly food waste collection with alternate weekly collection of recyclables and residual waste by two-compartment collection vehicle is the best system in terms of fuel consumption in most situations, while weekly single collection of the separated household waste is the worst. The reduction in fuel consumption for co-collection relative to single collection ranged from $7.4 \%$ to $22.4 \%$.

- The capture rate for food waste has little influence on fuel consumption per tonne for the residual waste collection, but the recyclables capture rate does affect this. At high capture rates $(70-100 \%)$ for food waste and recyclables, the fuel consumption per tonne of residual waste rises by $22-34 \%$. A pod vehicle with a large compartment volume capacity was always better than a rear split collection vehicle. A compartmentalized collection 
vehicle with a compartment split into 30:70 always performed better than one with two compartments of equal size.

- Co-collection of household waste is not always the best system, compared to collection in single-compartment vehicles. In some cases, separate collection of the household waste can consume less fuel than co-collection when the collection frequency is every two weeks.

\section{Acknowledgements}

This work was supported by the FP7 VALORGAS project (241334), and a PhD scholarship funded by the University of Southampton and Biogen Ltd.

\section{References}

[1] Nahman A, de Lange W, Oelofse S, Godfrey L. The costs of household food waste in South Africa. Waste Management. 2012;32:2147-53.

[2] Scottish Parliament. The Waste (Scotland) Regulations 2012 [Internet]. 2012 [cited 201214 August]. Available from: http://www.scottish.parliament.uk/ResearchBriefingsAndFactsheets/S4/SB_1218.pdf.

[3] DEFRA. Anaerobic Digestion Strategy and Action Plan - A commitment to increasing energy from waste through Anaerobic Digestion. London: Crown; 2011.

[4] Recycling waste world. ReFood calls for ban on landfilling food 2013 [cited 2013 December 14]. Available from: http://www.recyclingwasteworld.co.uk/news/refoodcalls-ban-landfilling-food.

[5] Letrecycle. Labour pledges to ban food waste from landfill 2013 [cited 2013 December 18]. Available from: http://www.letsrecycle.com/news/latestnews/compost/labour-pledges-to-ban-food-waste-from-landfill.

[6] GOV.UK. EU Commission review of waste policy and legislation: UK government response [Internet]. 2013 [cited 2013 December 19]. Available from: https://www.gov.uk/government/publications/eu-commission-review-of-waste-policyand-legislation-uk-government-response.

[7] Vision 2020. UK Roadmap to achieve zero food waste to landfill launched [Internet]. 2013 [cited 2013 December 10]. Available from: http://www.vision2020.info/news/november-2013/zero-food-waste/.

[8] DEFRA. Government Review of Waste Policy in England 2011. London: Crown; 2011.

[9] Mendoza JE, Castanier B, Guéret C, Medaglia AL, Velasco N. A memetic algorithm for the multi-compartment vehicle routing problem with stochastic demands. Computers \& Operations Research. 2010;37:1886-98. 
[10] Derigs U, Gottlieb J, Kalkoff J, Piesche M, Rothlauf F, Vogel U. Vehicle routing with compartments: applications, modelling and heuristics. OR Spectrum. 2011;33:885914.

[11] WRAP. Evaluation of the WRAP Separate Food Waste Collection Trials. Banbury: WRAP; 2009.

[12] Tai J, Zhang W, Che Y, Feng D. Municipal solid waste source-separated collection in China: A comparative analysis. Waste Management. 2011;31:1673-82.

[13] Bernstad A. Household food waste management - Evaluation of current status and potential improvements using life-cycle assessment methodology. Sweden: Technical University of Denmark; 2012.

[14] Eunomia. Dealing with food waste in the UK. Bristol: Eunomia Research \& Consulting Ltd, 2007.

[15] Everett JW, Shahi S. Curbside Collection of Yard Waste: I. Estimating Route Time. Journal of Environmental Engineering. 1996;122:107-14.

[16] Sonesson U. Modelling of waste collection-a general approach to calculate fuel consumption and time. Waste Management and Research. 2000;18:115-23.

[17] European Environment Agency. EMEP/EEA air pollutant emission inventory guidebook - 2009. Luxembourg: Publications Office of the European Union, 2009. (no. EEA Technical report no 12/2013).

[18] Willis V. Critical evaluation of the energy requirements of food waste collection schemes. Southampton: University of Southampton; 2010.

[19] Nguyen TTT, Wilson BG. Fuel consumption estimation for kerbside municipal solid waste (MSW) collection activities. Waste Management \& Research. 2010;28:289-97.

[20] Boriboonsomsin K, Barth M. Impacts of road grade on fuel consumption and carbon dioxide emissions evidenced by use of advanced navigation systems. Transportation Research Record: Journal of the Transportation Research Board. 2009;2139:21-30.

[21] Tchobanoglous GK, Frank. Handbook of Solid Waste Management. second ed. USA: McGraw Hill; 2002.

[22] Zamorano M, Molero E, Grindlay A, Rodríguez ML, Hurtado A, Calvo FJ. A planning scenario for the application of geographical information systems in municipal waste collection: A case of Churriana de la Vega (Granada, Spain). Resources, Conservation and Recycling. 2009;54:123-33.

[23] Defra. Defra EV0801 National compositional estimates for local authority collected waste and recycling in England, 2010/11 In: Defra, editor. London: Crown; 2012.

[24] Baumgart S, Flacke J, Grüger C, Lütke P, Rüdiger A. Klein-und MittelstädteVerkleinerte Blaupausen der Großstadt. Dokumentation des Expertenkolloquiums am. 2004;29. 
[25] VALORGAS. D6.3: Output from an energy and carbon footprint model verified against primary data collected as part of the research [Internet]. 2013 [cited 20145 May]. Available from: http://www.valorgas.soton.ac.uk/deliverables.htm.

[26] Larsen AW, Vrgoc M, Lieberknecht P, Christensen TH. Diesel consumption in waste collection and transport and its environmental significance. Waste Management \& Research. 2009.

[27] Chen T-C, Lin C-F. Greenhouse gases emissions from waste management practices using Life Cycle Inventory model. Journal of Hazardous Materials. 2008;155:23-31.

[28] Tanskanen J-H, Kaila J. Comparison of methods used in the collection of sourceseparated household waste. Waste Management \& Research. 2001;19:486-97.

[29] Smyth PM. An assessment of a source segregated food waste collection scheme [dissertation]. Southampton: University of Southampton; 2010. 
Table 1. Input values used in the collection model

\begin{tabular}{lll}
\hline Parameter & Value & Units \\
\hline General information: & & \\
Number of households & 20000 & $\mathrm{hh}$ \\
Amount of food waste generated & 2.38 & $\begin{array}{l}\mathrm{kg} \mathrm{hh}^{-1} \mathrm{day}^{-1} \\
\text { collectors }\end{array}$ \\
Number of collector(s) & 2 & \\
Time: & & \\
Working hours & 6 & hours \\
Break & 30 & $\mathrm{mins}$ \\
Traffic congestion & 0 & mins \\
Pick up of crew members & 5 & mins \\
Fuel filling & 10 & $\mathrm{mins}$ \\
Depot to collection area & 15 & $\mathrm{mins}$ \\
Collection area to unloading site & 15 & $\mathrm{mins}$ \\
At unloading site & 30 & $\mathrm{mins}$ \\
Travel time to unloading site from part way around the collection & 15 & $\mathrm{mins}$ \\
For intermediate unloading & 15 & $\mathrm{mins}$ \\
Food waste bin pick-up & 21.6 & $\mathrm{sec}$ \\
Residual or recycling bin pick-up & 33 & $\mathrm{sec}$ \\
& & \\
Fuel consumption: & & \\
Speed in transportation & 50 & $\mathrm{~km} \mathrm{~h}$ \\
Speed in collection & 10 & $\mathrm{~km} \mathrm{~h}$ \\
Factor for using hydraulic system during collection & 1.35 & \\
Distance: & & \\
From depot to collection area & & \\
From collection to unloading site & 12.5 & $\mathrm{~km}$ \\
Between houses & 12.5 & $\mathrm{~km}$ \\
Intermediate trip (unloading site to/from part way around the & 0.015 & $\mathrm{~km}$ \\
collection) & 12.5 & $\mathrm{~km}$ \\
\hline
\end{tabular}

Table 2. Composition of kerbside household waste used in the modelling

\begin{tabular}{ll}
\hline Waste type & Composition $(\%)$ \\
\hline Paper and card & 24.85 \\
Food & 24.1 \\
Garden \& other organic waste & 13.45 \\
Plastics & 10.92 \\
Glass & 6.23 \\
Metals & 3.3 \\
Wood & 0.84 \\
Textiles & 2.93 \\
WEEE & 1.03 \\
Others & 12.35 \\
\hline
\end{tabular}


Table 3. Specification of the collection vehicles used in the model

\begin{tabular}{llllll}
\hline & & & & \multicolumn{2}{l}{ Compartment size } \\
\cline { 5 - 6 } Code & $\begin{array}{l}\text { GVW } \\
\text { (tonnes) }\end{array}$ & $\begin{array}{l}\text { Payload } \\
\text { (tonnes) }\end{array}$ & $\begin{array}{l}\text { Number of } \\
\text { compartment(s) }\end{array}$ & Small $\left(\mathrm{m}^{3}\right)$ & Large $\left(\mathrm{m}^{3}\right)$ \\
\hline $3.5 \mathrm{t}$ & 3.5 & 0.715 & 1 & 5.5 & -- \\
$7.5 \mathrm{t}$ & 7.5 & 3.58 & 1 & 5 & -- \\
$12 \mathrm{t}$ & 12 & 3.74 & 1 & 10 & -- \\
$15 \mathrm{t}$ & 15 & 5.9 & 1 & 13 & -- \\
$18 \mathrm{t}$ & 18 & 7.75 & 1 & 15 & -- \\
$26 \mathrm{t}$ & 26 & 12.842 & 1 & 25 & - \\
Duo1 & 26 & 11.77 & 2 & 5 & 13.89 \\
Duo2 & 26 & 11.57 & 2 & 7 & 13.89 \\
Duo3 & 26 & 11.26 & 2 & 7 & 16.45 \\
Twin1 & 26 & 10.58 & 2 & 10 & 10 \\
Twin2 & 23 & 9.28 & 2 & 5 & 10 \\
Twin3 & 26 & 10.88 & 2 & 6 & 14 \\
\hline
\end{tabular}

Table 4. Nine scenarios for kerbside household waste collection systems

\begin{tabular}{|c|c|}
\hline Scenario & Description \\
\hline 1 & $\begin{array}{l}\text { Weekly separate collections of recyclables, residual and food waste by single- } \\
\text { compartment RCV }\end{array}$ \\
\hline 2 & $\begin{array}{l}\text { Alternate fortnightly collection of recyclables and residual waste and weekly collection } \\
\text { of food waste and by single-compartment RCV }\end{array}$ \\
\hline 3 & $\begin{array}{l}\text { Weekly co-collection of recyclables and residual waste by compartmentalised RCV, } \\
\text { weekly collection using single-compartment RCV for food waste }\end{array}$ \\
\hline 4 & $\begin{array}{l}\text { Fortnightly co-collection of recyclables and residual waste by compartmentalised RCV, } \\
\text { weekly collection using single-compartment RCV for food waste }\end{array}$ \\
\hline 5 & $\begin{array}{l}\text { Weekly co-collection of recyclables and food waste by compartmentalised RCV, weekly } \\
\text { collection using single-compartment RCV for residual waste }\end{array}$ \\
\hline 6 & $\begin{array}{l}\text { Weekly co-collection of recyclables and food waste by compartmentalised RCV, } \\
\text { fortnightly collection using single-compartment RCV for residual waste }\end{array}$ \\
\hline 7 & $\begin{array}{l}\text { Weekly co-collection of residual waste and food waste by compartmentalised RCV, } \\
\text { weekly collection using single compartment RCV for recyclables }\end{array}$ \\
\hline 8 & $\begin{array}{l}\text { Weekly co-collection of residual waste and food waste by compartmentalised RCV, } \\
\text { fortnightly collection using single compartment RCV for recyclables }\end{array}$ \\
\hline 9 & $\begin{array}{l}\text { Weekly food waste collection with alternate weekly collection of residual waste and } \\
\text { recyclables }\end{array}$ \\
\hline
\end{tabular}


Table 5. Optimum single compartment collection vehicle in different collection scenarios at capture rates from $10 \%$ to $100 \%$

\begin{tabular}{|c|c|c|c|c|c|}
\hline \multirow{2}{*}{$\begin{array}{l}\text { Capture rate of } \\
\text { recyclables and food } \\
\text { waste }(\%)\end{array}$} & \multicolumn{2}{|c|}{ Weekly collection } & \multicolumn{3}{|c|}{ Fortnightly collection } \\
\hline & Food waste & Co-recyclable & $\begin{array}{l}\text { Residual } \\
\text { waste }\end{array}$ & Co-recyclable & $\begin{array}{l}\text { Residual } \\
\text { waste }\end{array}$ \\
\hline 10 & 3.5-tonne & 18-tonne & 26-tonne & 12-tonne & 26-tonne \\
\hline 20 & 3.5-tonne & 12-tonne & 26-tonne & 12-tonne & 26-tonne \\
\hline 30 & 12-tonne & 7.5-tonne & 26-tonne & 15-tonne & 26-tonne \\
\hline 40 & 7.5-tonne & 12-tonne & 26-tonne & 18-tonne & 26-tonne \\
\hline 50 & 7.5-tonne & 12-tonne & 26-tonne & 26-tonne & 26-tonne \\
\hline 60 & 12-tonne & 15-tonne & 26-tonne & 26-tonne & 26-tonne \\
\hline 70 & 12-tonne & 18-tonne & 18-tonne & 18-tonne & 26-tonne \\
\hline 80 & 12-tonne & 18-tonne & 18-tonne & 18-tonne & 26-tonne \\
\hline 90 & 12-tonne & 18-tonne & 12-tonne & 18-tonne & 26-tonne \\
\hline 100 & 15-tonne & 18-tonne & 12-tonne & 18-tonne & 12-tonne \\
\hline
\end{tabular}

Table 6. Optimum compartmentalised collection vehicle for co-collection of two waste types at capture rates from $10 \%$ to $100 \%$

\begin{tabular}{|c|c|c|c|c|c|c|}
\hline \multirow{2}{*}{$\begin{array}{l}\text { Capture rate of } \\
\text { the recyclable } \\
\text { and food waste } \\
(\%)\end{array}$} & \multicolumn{3}{|c|}{ Weekly co-collection } & \multirow{2}{*}{$\begin{array}{l}\text { Fortnightly } \\
\text { co-collection }\end{array}$} & \multicolumn{2}{|c|}{$\begin{array}{l}\text { Weekly food waste with } \\
\text { alternate weekly collection } \\
\text { of }\end{array}$} \\
\hline & $\begin{array}{l}\text { Recyclable/R } \\
\text { esidual }\end{array}$ & $\begin{array}{l}\text { Recyclable/ } \\
\text { Food waste }\end{array}$ & $\begin{array}{l}\text { Residual/ } \\
\text { Food } \\
\text { waste }\end{array}$ & & Recyclables & Residual \\
\hline 10 & Duo3 & Duo2 & Duo3 & Duo3 & Twin3 & Duo3 \\
\hline 20 & Duo3 & Duo2 & Duo3 & Duo3 & Duo3 & Duo3 \\
\hline 30 & Duo3 & Duo2 & Duo3 & Duo3 & Duo1 & Duo3 \\
\hline 40 & Duo3 & Duo3 & Duo3 & Duo3 & Duo3 & Duo3 \\
\hline 50 & Duo3 & Twin1 & Duo3 & Duo3 & Duo1 & Duo3 \\
\hline 60 & Duo3 & Duo2 & Duo3 & Duo3 & Duo3 & Duo3 \\
\hline 70 & Duo1 & Duo2 & Duo3 & Duo3 & Duo1 & Duo3 \\
\hline 80 & Twin1 & Duo3 & Duo3 & Twin1 & Duo3 & Duo3 \\
\hline 90 & Twin1 & Duo2 & Duo3 & Twin1 & Duo3 & Duo3 \\
\hline 100 & Duo2 & Duo2 & Twin1 & Duo3 & Duo3 & Duo3 \\
\hline
\end{tabular}




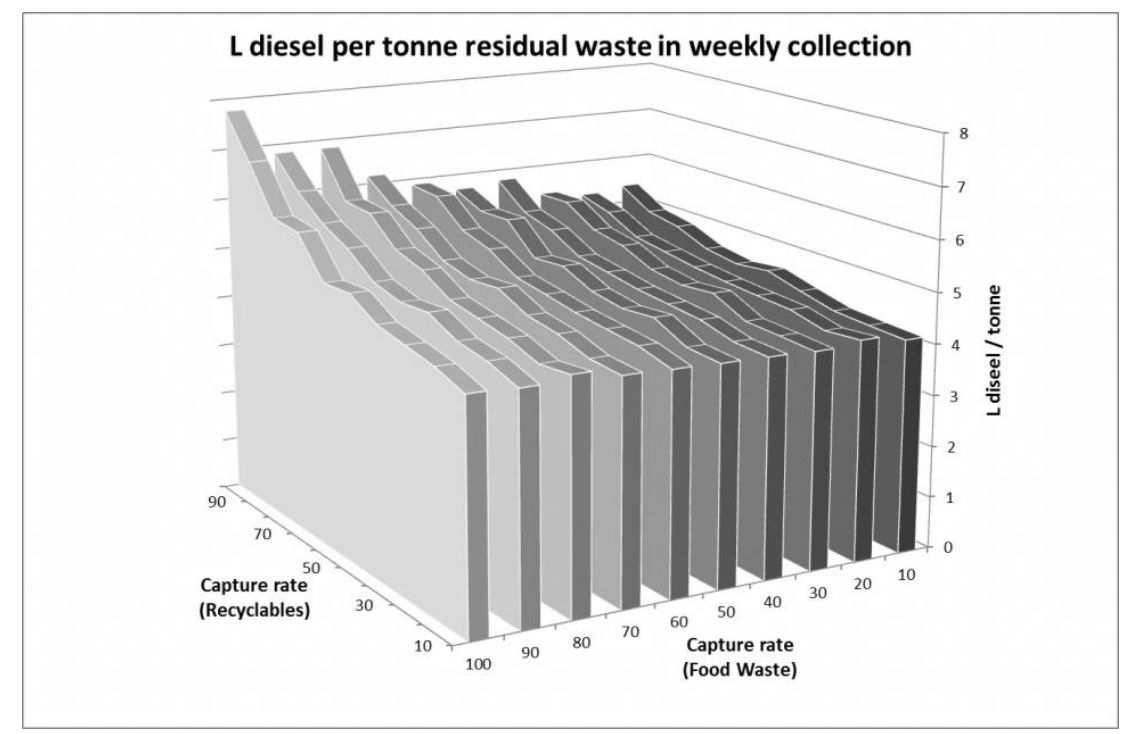

Figure 1. Fuel consumption per tonne of residual waste at different capture rates for food waste and recyclables (Weekly collection)

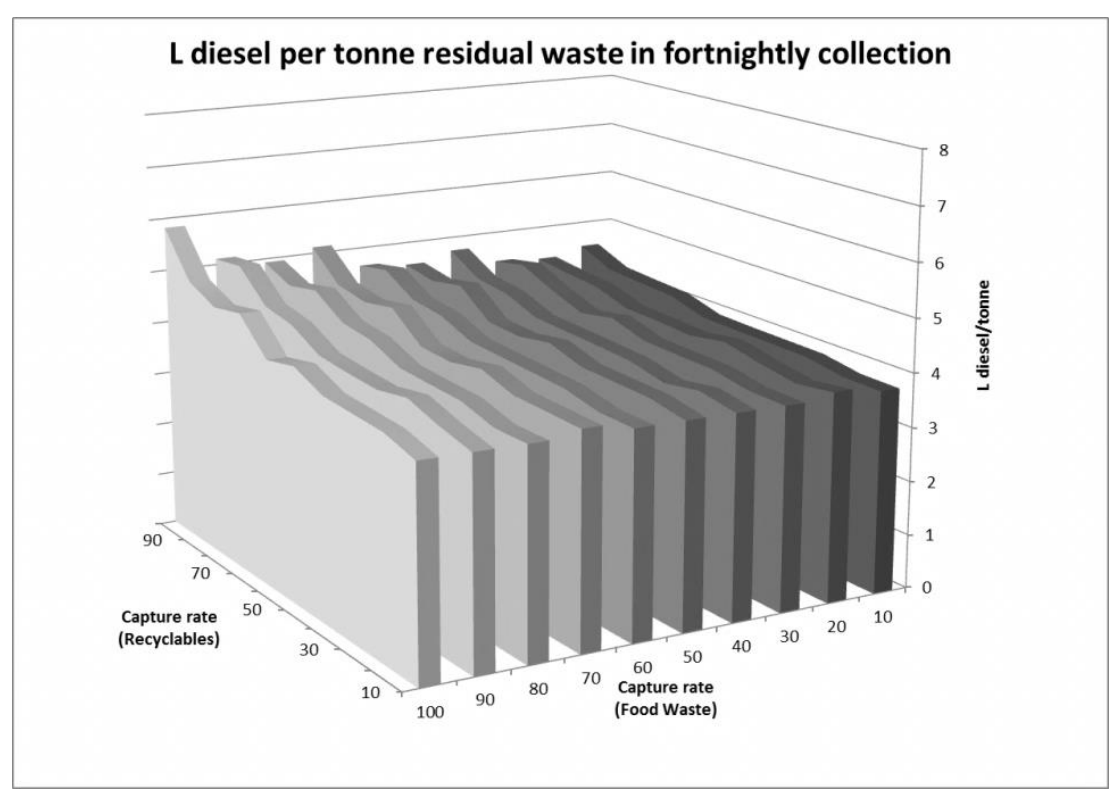

Figure 2. Fuel consumption in collection one tonne of residual waste at different capture rate for food waste and recyclables (Fortnightly collection) 


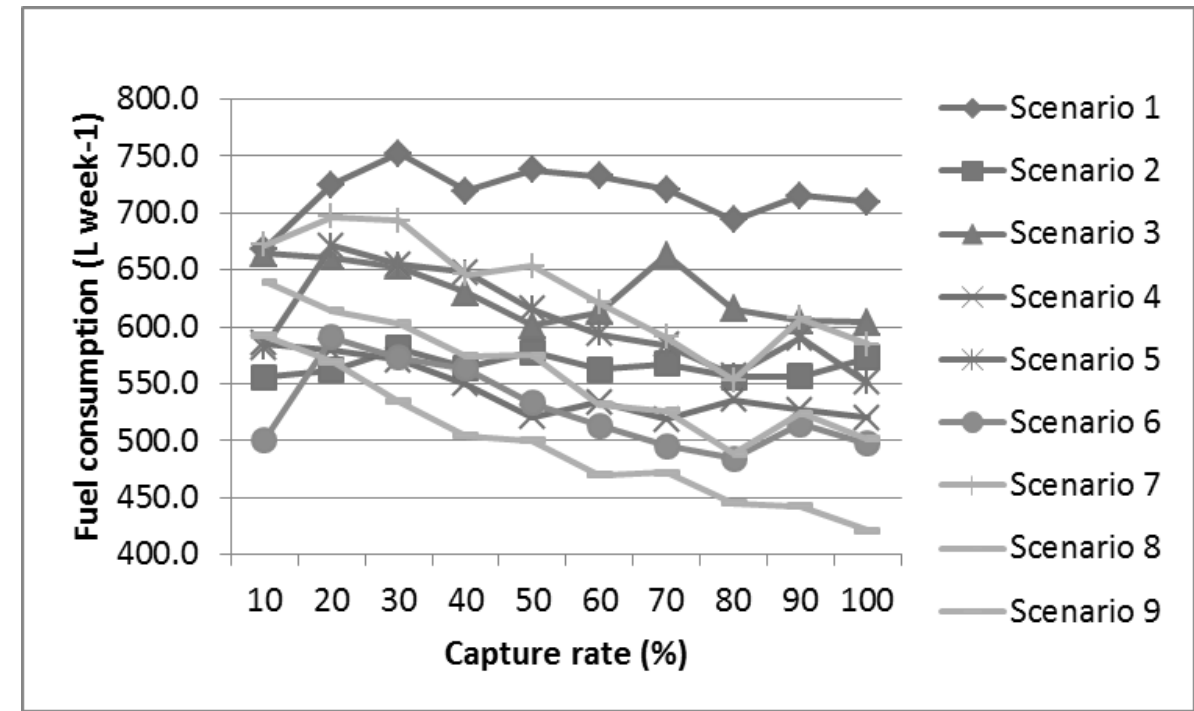

Figure 3. Best outcome with respect to fuel consumption for collection of the whole household waste stream, for each capture rate and scenario tested

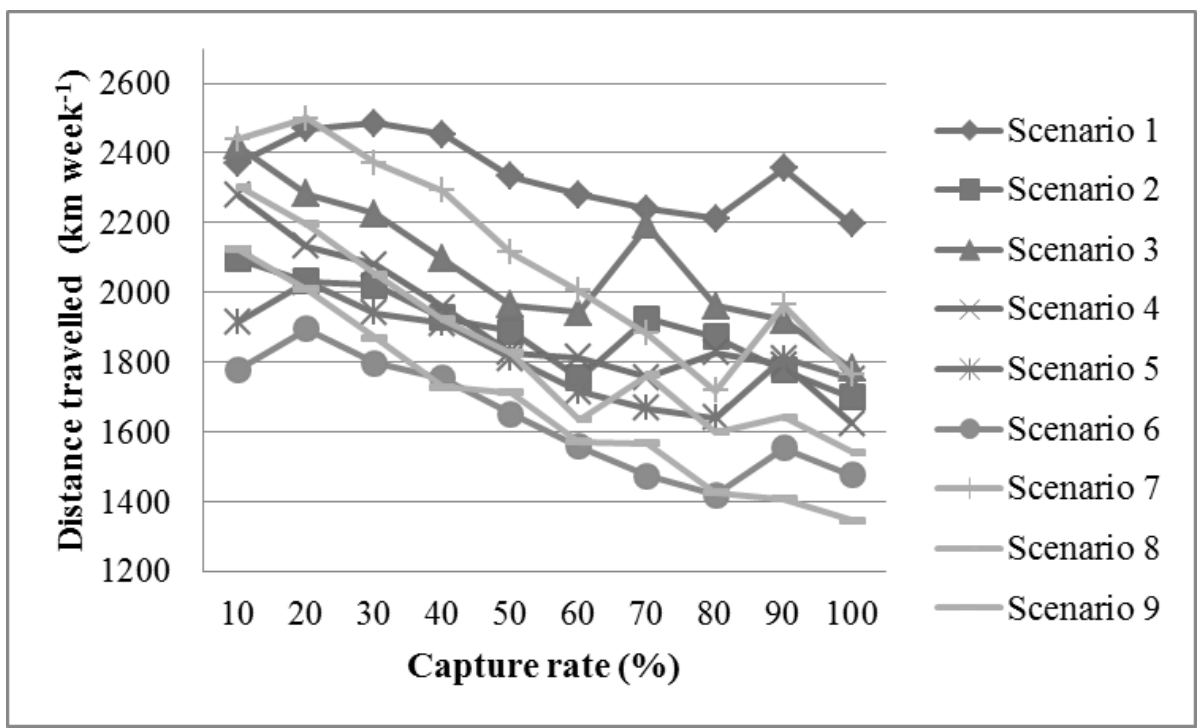

Figure 4. Best outcome with respect to travel distance for collection of the whole household waste stream, for each capture rate and scenario tested 


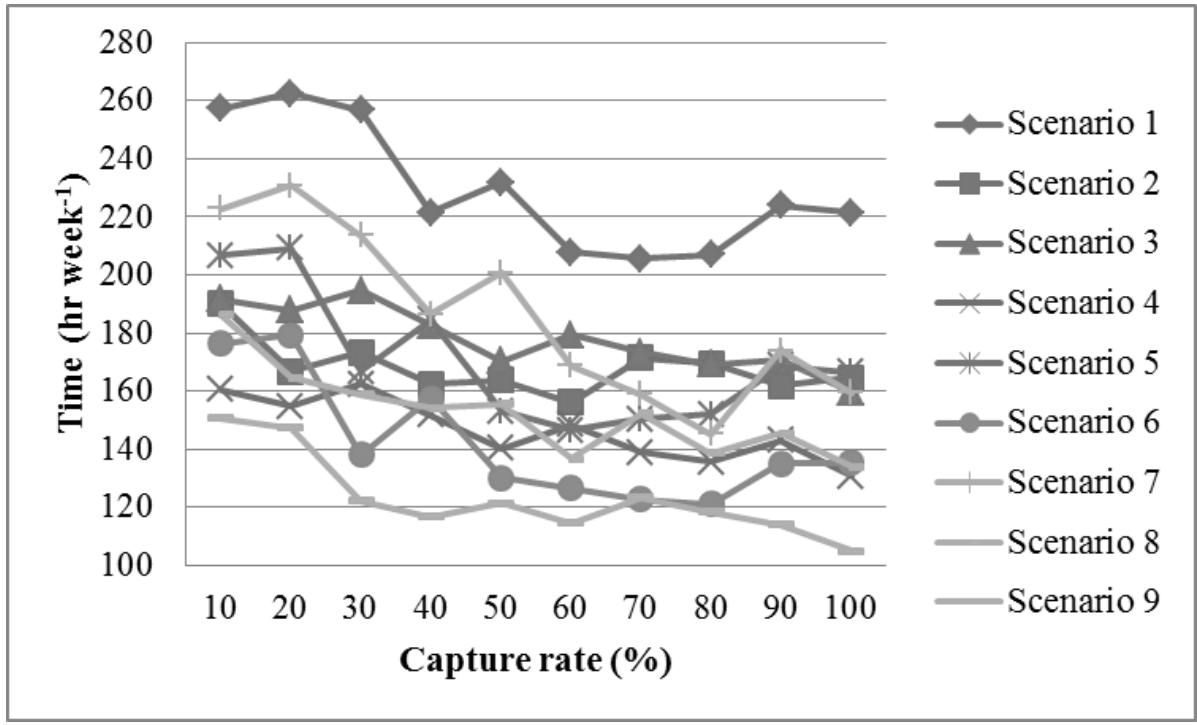

Figure 5. The minimum working hours spent per week for collection of the whole household waste stream for each capture rate and scenario tested 